\title{
Effect of Different Concentrations of Orange Juice for in Vitro Regeneration and Multiplication of Cocoyam (Taro)
}

\author{
Alfred O. Ubalua ${ }^{*}$, Ahamefula I. Ikpeama ${ }^{1}$, Onyinyechi D. Okeagu ${ }^{2}$ \\ ${ }^{1}$ Plant Tissue Culture Unit, Biotechnology Research and Development Center, National Root Crops Research \\ Institute (NRCRI) Umudike, Umuahia, Nigeria \\ ${ }^{2}$ Yam Programme, National Root Crops Research Institute (NRCRI) Umudike, Umuahia, Nigeria \\ Email: ${ }^{*}$ alfreduba@yahoo.com
}

Received 16 June 2015; accepted 18 October 2015; published 21 October 2015

Copyright (C) 2015 by authors and Scientific Research Publishing Inc.

This work is licensed under the Creative Commons Attribution International License (CC BY).

http://creativecommons.org/licenses/by/4.0/

(c) (i) Open Access

\begin{abstract}
Taro (Colocasia esculenta) and tannia (Xanthosoma sagittifolium) are commonly referred to as cocoyam in Nigeria. They are cherished for their rich taste, nutritional and medicinal properties. Traditionally, cocoyams are vegetatively propagated from tuber fragments, a practice that encourages pathogen distribution. For rapid multiplication and production of quality planting materials, tissue culture technology offers promising alternative compared to the traditional production methods. In this study different concentrations of ripped sweet orange (Citrus sinensis) juice were screened for regeneration and multiplication of 2 months old in vitro cocoyam shoot explants. Among the concentrations, maximum numbers of roots $(37 \pm 5)$ were observed in Murashige and Skoog (MS) medium supplemented with $10 \%$ orange juice after 8 weeks in culture compared to 16 \pm 4 (roots) observed in the control medium. On shoot multiplicity, $16 \pm 3$ shoots were induced in the control medium in contrast to $12 \pm 0.8$ shoots in the MS medium supplemented with $10 \%$ orange juice after 8 weeks of culture. Higher concentrations (25\% and $35 \%)$ of the orange juice supplemented medium resulted in concomitant inhibition of all the growth parameters. The study successfully established that ripped orange juice could substitute the use of conventional growth hormones cytokinins (BAP) and auxins (NAA) in in vitro regeneration and rapid multiplication of cocoyam shoot explants.
\end{abstract}

\section{Keywords}

Taro, Orange Juice, Shoot Explants, In Vitro Regeneration, Rapid Multiplication

\footnotetext{
${ }^{*}$ Corresponding author.
}

How to cite this paper: Ubalua, A.O., Ikpeama, A.I. and Okeagu, O.D. (2015) Effect of Different Concentrations of Orange Juice for in Vitro Regeneration and Multiplication of Cocoyam (Taro). American Journal of Plant Sciences, 6, 2569-2575. http://dx.doi.org/10.4236/ajps.2015.616259 


\section{Introduction}

It is 113 years since the concept of isolation and growth of plant cells in artificial culture medium was proposed by Gotlieb Haberlandt. Eighty years later, precisely in 1983, the first transgenic plant was engineered. The two events (1902 and 1983), marked the beginning in our long scientific journey towards today’s achievements in the plant and agricultural biotechnology revolution [1] [2]. The developments in plant tissue culture that have taken place in the last 45 years have revolutionized agricultural scene in a number of fronts including rapid production of mass quantity of uniform disease-free plants from a single explant, genetic engineering, callus induction, anther culture, protoplast culture, somatic embryogenesis, and genetic transformation of plants. Several researchers have reported on the production of improve taro cultivars through tissue culture [3]-[5]. De novo regeneration in taro has also been reported [6]-[9]. Production of improved taro varieties via genetic transformation offers an attractive alternative to conventional breeding. This technique was successfully carried out using both Agrobacterium tumefaciens and microprojectile bombardment of regenerable embryogenic suspension [9]-[12] and regenerable callus [13] [14]. Tissue culture techniques are now an attractive field of biotechnological research, and their roles are presently exploited in the areas of large scale clonal propagation, crop improvement, and conservation of plant genetic resources. Another modern extension of this technology is in phytosanitory germplasm transfer across international and inter-regional boundaries. It is therefore hopeful that these biotechnology alternatives may offer solutions to the contrasting reports on the dormancy and viability of taro seeds produced by sexual hybridization [15] [16].

Plant physiological processes are regulated by chemical signals known as plant growth regulators (PGRs). They are normally active at very low concentrations in plants. Indeed for the specific regulation of many plant processes and the differentiation of cells into specific plant parts, a variety of ratios and concentrations of these plant hormones are required rather than a single hormone acting alone [17]. They may act as both stimulators and inhibitors of growth, and could cause different plant parts (shoots, buds and roots) to respond differently, although the proportion of auxins (NAA) to cytokinins (BAP) determines the type and extent of organogenesis in plant cell cultures [18] [19]. Currently, great interest has been on developing technologies based on the use of natural fruit juices as growth hormones, carbon and vitamin sources for in vitro regeneration and propagation of plantlets in tissue culture media. Orange (Citrus sinensis) juice is tasty and nutritious. It is composed of vitamin C (82 mg), thiamin (0.28 mg), folate (45 mcg DFE), vitamin B6 (0.13 mg), vitamin A (194 IU), niacin (0.70 $\mathrm{mg})$, potassium (473 mg), magnesium (27 mg), calcium (25/350 - $500 \mathrm{mg})$, iron (0.42 mg) and sodium (2 mg) [20]. The use of natural plant products such as fruit juices could enhance the usefulness of plants as renewable resources of valuable chemicals and can be optimized to play an increasingly significant role in commercial development of new products for regulating plant growth [21].

Production challenges confronting cocoyam cultivation in the last three decades in Nigeria ranges from scarcity of quality planting materials, low multiplication ratio to incidences of pests and diseases [22]. Traditionally, cocoyams are vegetatively propagated from tuber fragments, a practice that encourages pathogen distribution. Furthermore, cocoyam rarely flowers and when it flowers, the flowers are protogynous which makes the use of classical breeding difficult. Successful inductions of flowers, after treatment with gibberellic acid have been reported [23]-[26]. Presently tissue culture techniques offer exciting possibilities for sustainable production and rapid generation of millions of disease-free healthy and vigorous plantlets in one year irrespective of seasons and in a relatively small space. Fruit like sweet orange (Citrus sinensis) is abundant in Nigeria and a valuable percentage are perennially lost due to inadequate storage and processing. A ubiquitous and easy growing tree, but the fruits are prone to postharvest rot in a short period of about 2 weeks. In this study therefore, the potential of substituting cheap and locally available sweet orange juice excluding the conventional growth hormones (NAA and BAP) on in vitro regeneration and multiplication of cocoyam shoot explants is explored.

\section{Materials and Methods}

\subsection{Extraction of the Orange Juice}

Ripped oranges (Citrus sinensis) were washed in running tap water, followed by immersion in $70 \%$ ethanol for 20 min. Sterilization was carried out in 3.5\% sodium hypochlorite solution in combination with 2 drops of Tween 20 for 15 min. This was followed by rinsing three times in sterile distilled water (10 min per each rinse) and allowed to dry at room temperature. The oranges were cut with sterile scalpel and hand-squeezed. The pulps were sieved through sterile cheesecloth and centrifuged for 20 minutes at $2000 \mathrm{rpm}$. 


\subsection{Culture Medium and Establishment of Cultures}

The control medium was composed of Murashige and Skoog's basal medium supplemented with vitamins, myoinositol, L-cysteine, BAP, NAA, gelrite and sucrose. Other media were composed of all the aforementioned components with different concentrations $(10 \%, 15 \%, 25 \%$, and $35 \%)$ of orange juice excluding the two growth hormones (BAP and NAA) (Table 1). All the media were supplemented with $3 \%$ sucrose, adjusted to $\mathrm{pH} 5.8$ with $1 \mathrm{~N} \mathrm{H}_{2} \mathrm{SO}_{4}$ and/or $1 \mathrm{~N} \mathrm{NaOH}$ before adding $2 \mathrm{~g} / \mathrm{l}$ of gelrite and sterilizing by autoclaving at $121^{\circ} \mathrm{C}$ for 20 minutes. Four weeks old cocoyam shoot explants (Colocasia esculenta) were aseptically trimmed with sterile forceps and scalpel in a laminar air flow hood. The base of the explants were neatly sliced-off and inoculated singly into sterile test tubes containing $10 \mathrm{ml}$ of the sterile MS media. The test tubes were sealed properly with parafilm and clearly labeled before growing the cultures at a temperature of $28^{\circ} \mathrm{C} \pm 2^{\circ} \mathrm{C}$ for $16 \mathrm{~h}$ photoperiod and $8 \mathrm{~h}$ darkness at light intensity of 2000 - 3000 lux for 8 weeks. All treatments consisted of three replicates and each replicate contained eight shoot explants. Shoot height, number of roots, number of shoots and leaves were recorded after every 2 weeks for 8 weeks in culture. Data were analyzed using DMRT test at $5 \%$ level of significance.

\section{Results and Discussion}

The results of in vitro regeneration and multiplication of young cocoyam shoot explants are as captured in Tables 2-5. Various concentrations of the orange juice in the culture media induced varied growth responses on

Table 1. Media compositions for in vitro regeneration and multiplication of cocoyam plantlets.

\begin{tabular}{cc}
\hline Media description & Components \\
\hline Murashige and Skooge (MS) (control) & MS media, vitamin mixture, myo-inositol, L-cysteine, BAP, NAA, gelrite + sucrose \\
MS + 10\% orange juice & MS media, vitamin mixture, myo-inositol, L-cysteine, $10 \%$ orange juice, gelrite + sucrose. \\
MS + 15\% orange juice & MS media, vitamin mixture, myo-inositol, L-cysteine, 15\% orange juice, gelrite + sucrose. \\
MS + 25\% orange juice & MS media, vitamin mixture, myo-inositol, L-cysteine, $25 \%$ orange juice, gelrite + sucrose. \\
MS + 35\% orange juice & MS media, vitamin mixture, myo-inositol, L-cysteine, $35 \%$ orange juice, gelrite + sucrose. \\
\hline
\end{tabular}

Table 2. Mean number of roots induced from the in vitro cocoyam shoot explants raised in the media.

\begin{tabular}{|c|c|c|c|c|}
\hline Media description & 2 weeks & 4 weeks & 6 weeks & 8 weeks \\
\hline MS (control) & $0^{\mathrm{b}}$ & $0^{\mathrm{b}}$ & $8 \pm 2^{c}$ & $16 \pm 4^{\mathrm{c}}$ \\
\hline MS $+10 \%$ orange juice & $8 \pm 2^{\mathrm{a}}$ & $17 \pm 4^{\mathrm{a}}$ & $28 \pm 6^{\mathrm{a}}$ & $37 \pm 5^{\mathrm{a}}$ \\
\hline MS $+15 \%$ orange juice & $0^{\mathrm{b}}$ & $0^{\mathrm{b}}$ & $12 \pm 3^{b}$ & $18 \pm 4^{\mathrm{b}}$ \\
\hline MS + $25 \%$ orange juice & $0^{\mathrm{b}}$ & $0^{\mathrm{b}}$ & $8 \pm 1.6^{c}$ & $14 \pm 3^{\mathrm{d}}$ \\
\hline MS $+35 \%$ orange juice & $0^{\mathrm{b}}$ & $0^{\mathrm{b}}$ & $6 \pm 0.8^{d}$ & $10 \pm 0.9^{\mathrm{e}}$ \\
\hline
\end{tabular}

Key: Values represents mean \pm standard errors for three replications for each treatment. Mean in a column with the same superscript letter do not differ significantly according to DMRT at 5\% level of probability.

Table 3. Mean number of leaves produced by the in vitro cocoyam shoot explants raised in the media.

\begin{tabular}{|c|c|c|c|c|}
\hline Media description & 2 weeks & 4 weeks & 6 weeks & 8 weeks \\
\hline MS (control) & $4 \pm 0.3^{b}$ & $9 \pm 2^{b}$ & $16 \pm 4^{\mathrm{b}}$ & $24 \pm 5^{b}$ \\
\hline MS $+10 \%$ orange juice & $3 \pm 0.1^{\mathrm{c}}$ & $7 \pm 1.4^{\mathrm{c}}$ & $10 \pm 2^{\mathrm{d}}$ & $12 \pm 3^{\mathrm{e}}$ \\
\hline MS $+15 \%$ orange juice & $8 \pm 2^{\mathrm{a}}$ & $19 \pm 4^{\mathrm{a}}$ & $26 \pm 7^{\mathrm{a}}$ & $32 \pm 6^{\mathrm{a}}$ \\
\hline MS $+25 \%$ orange juice & $2 \pm 0.2^{\mathrm{d}}$ & $6 \pm 0.4^{\mathrm{d}}$ & $11 \pm 2.5^{c}$ & $19 \pm 3.8^{c}$ \\
\hline MS $+35 \%$ orange juice & $2 \pm 0.1^{\mathrm{d}}$ & $6 \pm 0.7^{\mathrm{d}}$ & $9 \pm 2^{e}$ & $18 \pm 4^{\mathrm{d}}$ \\
\hline
\end{tabular}

Key: Values represents mean \pm standard errors for three replications for each treatment. Mean in a column with the same superscript letter do not differ significantly according to DMRT at 5\% level of probability. 
Table 4. Mean shoot height $(\mathrm{cm})$ produced by the in vitro cocoyam shoot explants raised in the media.

\begin{tabular}{ccccc}
\hline Media description & 2 weeks & 4 weeks & $\mathbf{6}$ weeks & $\mathbf{8}$ weeks \\
\hline MS (control) & $1.4 \pm 0.1^{\mathrm{a}}$ & $2.15 \pm 0.3^{\mathrm{a}}$ & $3.6 \pm 0.04^{\mathrm{a}}$ & $5.15 \pm 0.2^{\mathrm{a}}$ \\
MS + 10\% orange juice & $1.2 \pm 0.3^{\mathrm{a}}$ & $2.13 \pm 0.1^{\mathrm{a}}$ & $3.8 \pm 0.2^{\mathrm{a}}$ & $5.23 \pm 0.03^{\mathrm{a}}$ \\
MS + 15\% orange juice & $1.2 \pm 0.04^{\mathrm{a}}$ & $2.13 \pm 0.01^{\mathrm{a}}$ & $3.1 \pm 0.4^{\mathrm{b}}$ & $5.09 \pm 0.1^{\mathrm{a}}$ \\
MS + 25\% orange juice & $0.87 \pm 0.02^{\mathrm{a}}$ & $1.62 \pm 0.03^{\mathrm{a}}$ & $3.2 \pm 0.05^{\mathrm{b}}$ & $4.77 \pm 0.06^{\mathrm{a}}$ \\
MS + 35\% orange juice & $0.64 \pm 0.03^{\mathrm{a}}$ & $1.52 \pm 0.02^{\mathrm{a}}$ & $2.8 \pm 0.1^{\mathrm{b}}$ & $4.33 \pm 0.6^{\mathrm{ab}}$ \\
\hline
\end{tabular}

Key: Values represents mean \pm standard errors for three replications for each treatment. Mean in a column with the same superscript letter do not differ significantly according to DMRT at 5\% level of probability.

Table 5. Mean number of multiple shoots induced from the in vitro cocoyam explants raised in the media.

\begin{tabular}{|c|c|c|c|c|}
\hline Media description & 2 weeks & 4 weeks & 6 weeks & 8 weeks \\
\hline MS (control) & $2 \pm 0.1^{\mathrm{b}}$ & $5 \pm 0.2^{\mathrm{c}}$ & $8 \pm 0.4^{\mathrm{b}}$ & $16 \pm 3^{\mathrm{a}}$ \\
\hline MS $+10 \%$ orange juice & $3 \pm 0.2^{\mathrm{a}}$ & $6 \pm 0.1^{\mathrm{b}}$ & $9 \pm 0.3^{\mathrm{a}}$ & $12 \pm 0.8^{\mathrm{b}}$ \\
\hline MS $+15 \%$ orange juice & $3 \pm 0.03^{\mathrm{a}}$ & $7 \pm 0.4^{\mathrm{a}}$ & $9 \pm 0.6^{a}$ & $11 \pm 2^{c}$ \\
\hline MS $+25 \%$ orange juice & $1 \pm 0.02^{\mathrm{c}}$ & $3 \pm 0.01^{\mathrm{e}}$ & $8 \pm 0.2^{\mathrm{b}}$ & $11 \pm 3.2^{c}$ \\
\hline MS $+35 \%$ orange juice & $1 \pm 0.04^{\mathrm{c}}$ & $4 \pm 0.3^{\mathrm{d}}$ & $8 \pm 0.5^{b}$ & $11 \pm 2.4^{c}$ \\
\hline
\end{tabular}

Key: Values represents mean \pm standard errors for three replications for each treatment. Mean in a column with the same superscript letter(s) do not differ significantly according to DMRT at $5 \%$ level of probability.

the in vitro culture of the cocoyam shoot explants. Regeneration and proliferation efficiency of the explants were higher in the MS media supplemented with $10 \%$ and $15 \%$ orange juice compared to the other treatments (Tables $2-5$ ). All the culture media except those supplemented with $25 \%$ and $35 \%$ orange juice concentrations induced optimal responses on regeneration and propagation of the explants. In $10 \%$ and $15 \%$ orange juice supplemented media, there were significant improvement in roots and leaf growth compared to the control medium (Table 2 \& Table 3). Development and proliferation of new roots were greatest in $10 \%$ orange juice supplemented MS medium (Table 2). Low concentrations of the orange juice may have favoured the initiation of numerous roots and leaf production in cocoyam compared to $25 \%$ and 35\% orange juice concentrations (Table 2 \& Table 3 respectively). But at 8 weeks of culture the superiority of the $10 \%$ orange juice supplemented medium was further demonstrated with marked profused root induction (37 \pm 5 ) against the other treatments (Table 2). Thus, the performance of the medium containing $10 \%$ orange juice concentration was significant over the other treatments including the control because at this concentration we observed the earliest root induction of $(8 \pm 2)$ in 2 weeks and a maximum proliferation of $37 \pm 5$ at 8 weeks (Table 2). The rooting efficiency and the number of roots regenerated per shoot were significantly $(\mathrm{P}<0.05)$ higher in $10 \%$ orange juice supplemented medium followed by a decrease when the orange juice concentration was increased to $15 \%, 25 \%$, and $35 \%$ (Table 2). The superior performance of the $10 \%$ orange juice supplemented medium could be that the plantlets will not need to expend energy to break down sucrose into utilizable monosaccharide [27]. Optimal growth and morphogenesis of tissues may vary for different plants according to their nutritional requirements [28]. Ikram-ul-Hag et al., [29], achieved maximum in vitro growth of cucumber (Cucumus sativus L.) in MS medium supplemented with 158 $\mathrm{ml}$ orange juice excluding growth hormones compared to the control medium and other media formulation containing apple, red grapes and strawberry juices.

The superiority of the orange juice supplemented medium over the control medium was further demonstrated on leaf induction and growth after 2, 4, 6, \& 8 weeks in culture (Table 3). At 15\% orange juice concentration in the MS medium, significant improvement in leaf production was observed after 2, 4, 6, \& 8 weeks in culture compared to the other treatments (Table 3). Leaf induction, shoot height development and shoot multiplication were observed after 2 weeks of culture (Tables 3-5). Although enhanced leaf induction were observed in the $2^{\text {nd }}$ week in the medium containing $15 \%$ orange juice, further increase in the concentration of the orange juice in the medium resulted in the significant decrease in the number of leaves produced per explants (Table 3). Higher 
concentrations might be inhibitory and could reverse the beneficial effects of the juice on the regeneration and growth of the plantlets. Thus, higher concentrations of the orange juice at $15 \%, 25 \%$ and $35 \%$ in the media inhibited roots regeneration and proliferation (Table 2). Similarly, leaf induction and growth were also inhibited at $25 \%$ and $35 \%$ orange juice concentration (Table 3 ).

The effects of the orange juice supplemented media were observed to be insignificant on shoot height (Table 4) and shoot multiplicity compared to the enhanced multiple shoot induction in the control medium after 8 weeks of culture (Table 5). Manawadu et al., [30] observed that the exact conditions that are necessary for regeneration of intact plantlets from cultured explants may vary for each plant species. In their in vitro study on shoot regeneration of Raphanus sativus, they achieved highest shoot height on MS medium containing $10 \%$ orange juice compared to $20 \%$ coconut water and $20 \%$ coconut milk. In this study we also observed highest shoot height after 6 and 8 weeks in culture at 10\% orange juice concentration compared to the other treatments (Table 4). Although the control medium induced the highest number of multiple shoots (16 \pm 3 ) after 8 weeks in culture compared to the other treatments (Table 5), the media containing $10 \%$ and $15 \%$ orange juice produced the highest number roots and leaves (Table $2 \&$ Table 3 respectively). Besides delayed root induction in the control medium and in the media supplemented with 15\%, 25\% \& 35\% orange juice concentration (Table 2) other growth parameters like leaves, shoot height and number of shoots responded at 2 weeks of culture (Tables 3-5). Thus, $8 \pm 2$ (leaves), $1.4 \pm 0.1 \mathrm{~cm}$ shoot height and $3 \pm 0.03$ number of shoots were observed in $15 \%$ orange juice supplemented medium, control medium, and 15\% orange juice supplemented medium (Tables 3-5) respectively. However at 2 and 4 weeks of culture, the performances of the cocoyam shoot explants were significantly different at various treatments considered (Table 5). Thus, at 2, 4, 6, \& 8 weeks of culture, $3 \pm 0.03,7 \pm$ 0.4, $9 \pm 0.3$ and $16 \pm 3$ number of shoots were observed suggesting that the control medium supported maximum shoot multiplicity of the cocoyam explants at 8 weeks of culture.

Orange juice, a complex organic extract used in this study contained carbohydrates, protein, several vitamins, lower levels of some amino acids and organic acids [31]. Any of the aforementioned components or other(s) yet unknown substances, alone or in combination might be a factor(s) enhancing plantlet regeneration compared to the control [31]. The present study revealed that 10\% - 15\% orange juice concentrations in the MS media were more suitable for in vitro regeneration and multiplication of cocoyam plantlets. At these concentrations, the level of organic acids, vitamins or other unknown substance(s) which may be responsible for promoting the growth of in vitro cocoyam plantlets may be optimum. Higher concentrations might be inhibitory and could reverse the beneficial effects of the juice on the regeneration and growth of the plantlets. Amazingly, multiple shoot formation was observed on all the growing plantlets on all the media type (Table 5) implying that such a trait may be inherent in the cocoyam crop. Therefore, shoot multiplicity of the cocoyam shoot explants in culture is another advantage that recommends tissue culture technique for rapid multiplication of disease-free healthy cocoyam plantlets. Hence, tissue culture application could be a valuable tool in mass production of disease-free healthy cocoyam planting materials compared to the traditional methods. In addition, supplementation of orange juice extract in culture medium is not cumbersome, but advantageous and a convenient approach to reduce cost of culture media. We also observed that the promotive effect of the orange juice extract concentration varied with the growth of the different organs of the plantlets as typified with that of the roots and the leaves at $10 \%$ and $15 \%$ respectively. The $10 \%$ and $15 \%$ orange juice supplemented media performed convincingly better than the control especially on roots and leaves regeneration and development (Table 2 and Table 3). Additionally, the incorporation of the orange juice did not trigger any form of morphogenic changes in the regenerated juvenile plantlets (Figures 1(a)-(e)) rather the regenerants on the orange juice supplemented media were more robust, greenish and even healthier (Figure 1(c) \& Figure 1(e)). The study has successfully developed a simple, cheap and reliable protocol for in vitro regeneration and multiplication of cocoyam plantlets. Further experiment will be exclusively on orange juice extract and agar as culture medium for in vitro regeneration and multiplication.

\section{Conclusion}

At $10 \%$ and $15 \%$ orange juice concentration, the supplemented media produced the best result, thus recommending its application for in vitro regeneration and multiplication of cocoyam plantlets. We observed that higher concentration of the orange juice ( $25 \%$ \& 35\%) in the MS medium resulted in the concomitant decrease in the growth responses of roots, leaves, shoot height and shoot multiplicity. Based on our results, we therefore concluded that orange juice at $10 \%$ and $15 \%$ concentrations in the MS media is a potential alternative organic 


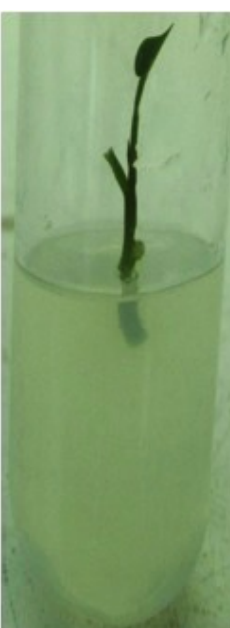

(a)

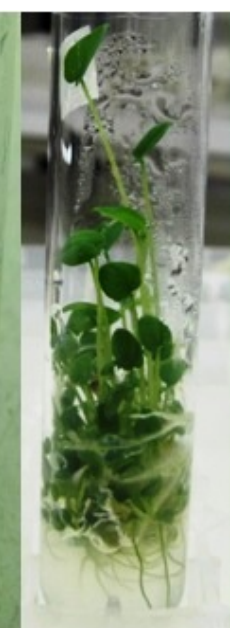

(b)

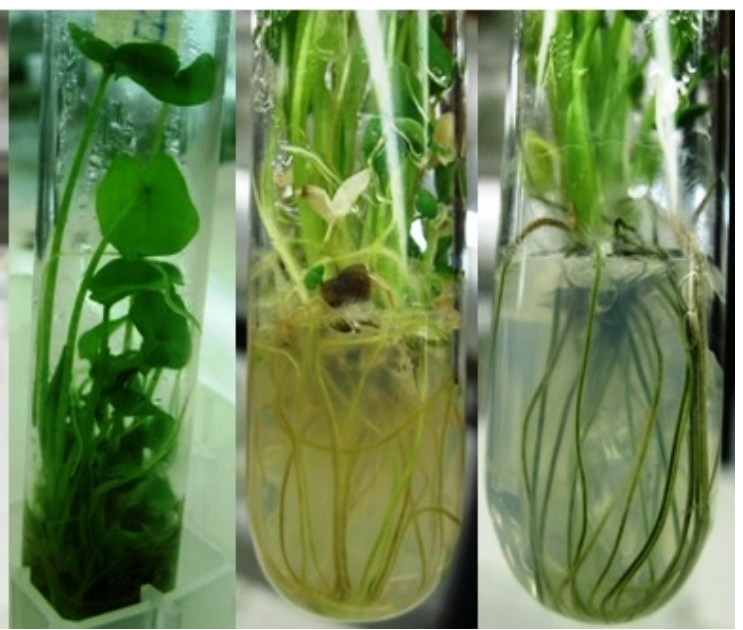

(d)

(e)

Figure 1. In vitro regeneration and multiplication of cocoyam plantlets, (a) growing cocoyam shoot explants; (b) shoot multiplication in the control medium (MS); (c) shoot multiplication in MS medium augmented with $10 \%$ orange juice; (d) root proliferation in the control medium (MS); (e) root proliferation in the MS medium augmented with $10 \%$ orange juice.

additive to synthetic growth hormones in the culture medium for in vitro regeneration and multiplication of cocoyam. Impressively, one cocoyam shoot explant could develop multiples of 9 new shoots in culture within 4 weeks. This cheap and straight forward approach may be economically feasible for large scale production of disease-free cocoyam planting materials through tissue culture technology.

\section{References}

[1] Altman, A. (2003) From Plant Tissue Culture to Biotechnology: Scientific Revolutions, Abiotic Stress Tolerance and Forestry. In Vitro Cellular Developmental Biology_Plant, 39, 75-84. http://dx.doi.org/10.1079/IVP2002379

[2] Ubalua, A.O. (2009) Transgenic Plants: Successes and Controversies. Biotechnology and Molecular Biology Reviews, 4, 118-127.

[3] Jackson, G.V.H., Ball, E.A. and Arditi, J. (1977) Tissue Culture of Taro (Colocasia esculenta (L.) Schott). Journal of Horticultural Science, 52, 373-382.

[4] Tuia, V.S. (1997) In Vitro Multiplication of Taro (Colocasia esculenta var. esculenta L. Schott), M. Agri.: University of the South Pacific.

[5] Deo, P.C., Tyagi, A.P., Taylor, M., Becker, D.K. and Harding, R.M. (2009) Improving taro (Colocasia esculenta var. esculenta) Production Using Biotechnological Approaches. South Pacific Journal of Natural Science, 27, 6-13. http://dx.doi.org/10.1071/SP09002

[6] Yam, T.W., Ichihashi, S. and Arditi, J. (1991) Callus Growth and Plantlet Regeneration in Taro, Colocasia esculenta var. esculenta (L.) Schott (Araceae). Annals of Botany, 67, 317-323.

[7] Thinh, N.T. (1997) Cryopreservation of Germplasm of Vegetatively Propagated Tropical Monocots by Vitrification. Doctoral Dissertation, Kobe University.

[8] Verma, V.M., Cho, J.J., Aikne, J. and David, J. (2004) High Frequency Plant Production of Taro (Colocasia esculenta (L.) Schott) by Tissue Culture. Proceedings for the 4th International Crop Science Congress, Brisbane.

[9] Deo, P.C. (2008) Somatic Embryogenesis and Transformation in Taro (Colocasia esculenta var. esculenta). Ph.D. Thesis, The University of the South Pacific, Suva.

[10] Aguado-Santacruz, G.A., Rascón-Cruz, Q., Cabrera-Ponce, J.L., Martínez-Hernández, A., Olalde-Portugal, V. and Herrera-Estrella, L. (2002) Transgenic Plants of Blue Grama Grass, Bouteloua gracilis (H.B.K.) Lag.ex. Steud., from Microprojectile Bombardment of Highly Chlorophyllous Embryogenic Cells. Theoretical and Applied Genetics, 104, 763-771. http://dx.doi.org/10.1007/s00122-001-0803-2

[11] Sahrawat, A.K., Becker, D., Lötticke, S. and Lörz, H. (2003) Genetic Improvement of Wheat via Alien Gene Transfer, an Assessment. Plant Science, 165, 1147-1168. http://dx.doi.org/10.1016/S0168-9452(03)00323-6

[12] ul-Haq, I. (2005) Callus Proliferation and Somatic Embryogenesis in Cotton (Gossypium hirsutum L.). African Journal 
of Biotechnology, 4, 206-209.

[13] He, X., Miyasaka, S., Fitch, M.M., Zhu, Y.J. and Moore, P.H. (2004) Transformation of Taro (Colocasia esculenta) with a Rice Chitinase Gene (Abstract). In Vitro Cellular and Developmental Biology-Plant, 40, 2104.

[14] He, X., Miyasaka, S., Fitch, M.M., Zhu, Y.J., Moore, P.H. and Zhu, Y.J. (2008) Agrobacterium tumefaciens-Mediated Transformation of Taro (Colocasia esculenta (L.) Schott) with a Rice Chitinase Gene for Improved Tolerance to a Fungal Pathogen Sclerotium rolfsii. Plant Cell Reports, 27, 903-909. http://dx.doi.org/10.1007/s00299-008-0519-8

[15] Straus, M.S., Michaud, J.D. and Arditi, J. (1979) Seed Storage and Germination and Seedling Proliferation in Taro (Colocasia esculenta (L.) Schott). Annals of Botany, 43, 603-612.

[16] Wang, J.K. (1983) Taro: A Review of Colocasia esculenta and Its Potential. University of Hawaii, Honolulu.

[17] Harms, C.L. and Oplinger, E.S. (1988) Plant Growth Regulators: Their Use in Crop Production. North Central Region Extension Publication 303, Wisconsin.

[18] Skoog, F. and Miller, R.A. (1957) Chemical Regulations of Growth and Organ Formation in Plant Tissue Culture in Vitro. Symposia of the Society for Experimental Biology, 11, 118-130.

[19] Nair, R.R., Kavitha, M., Thilaga, S. and Ganesh, D. (2012) Conservation and in Vitro Multiplication of Highly Endangered Indian Traditional Medicinal Plant (Morinda reticulata Gamble) through Nodal Explants. Plant Knowledge Journal, 1, 46-51.

[20] USDA (2008) USDA National Nutrient Database for Standard Reference, Release 21. NDB 09209.

[21] Ali, F.M., Ahsan, M., Saeed, N.A., Ahmed, M., Ali, Q., Kanwal, N., Tehseen, M.M., Ijaz, U., Bibi, I. and Niazi, N.K. (2014) Establishment and Optimization of Callus-to-Plant Regeneration System Using Mature Andimmature Embryos of Maize (Zea mays). International Journal of Agricultural Biology, 16, 11-117.

[22] Ubalua, A.O. and Chukwu, L.I. (2008) Potentials and Constraints of Cocoyam Production in Nigeria. Proceedings of the 42nd Annual Conference, Agricultural Society of Nigeria (ASN), Ebonyi State University, Abakaliki, 19-23 October 2008.

[23] Wilson, J.E. (1979) Cocoyam Breeding by Flower Induction, Pollination, and Germination. Manual Ser No. 4, IITA, Ibadan.

[24] Alamu, S., McDavid, C.R. and Duncan, E.J. (1982) Production of Viable Gibberellic Acid-Treated Tannia (Xanthosoma sagittifolium) Plants. Tropical Agriculture, 59, 323-334.

[25] Agueguia, A. and Nzietchueng, S. (1984) Production of Hybrid Xanthosoma sagitifolium and Test for Resistance to Phythium myriotylium. In: Terry, E.R., Doku, E.V., Arene, O.B. and Mahungu, N.M., Eds., Tropical Root Crops: Production and Uses in Africa, Proceedings of the 2nd Triennial Symposium of the International Society for Tropical Root Crops, Africa Branch, Douala, IDRC, Ottawa, Vol. 221, 169-171.

[26] Tambong, J.T. and Meboka, M. (1994) Cocoyam (Xanthosoma sagittifolium (L.)) Hybridization Studies: Pollen Viability and Seed Germination. Acta Horticulturae, 380, 448-459. http://dx.doi.org/10.17660/ActaHortic.1994.380.69

[27] Alkhateeb, A. (2008) Comparison Effects of Sucrose and Date Palm Syrup on Somatic Embryogenesis of Date Palm (Phoenix dactylifera L.). American Journal of Biotechnology and Biochemistry, 4, 19-23. http://dx.doi.org/10.3844/ajbbsp.2008.19.23

[28] Saad, A.I.M. and Elshahed, A.M. (2012) Plant Tissue Culture Media. In: Leva, A. and Rinaldi, L.M.R., Eds., Recent Advances in Plant in Vitro Culture, Chap. 2, InTech, Winchester, 29-40.

[29] Ikram-ul-Hag, A.Z., Taseer, M.G., Mukesh, D.M.U. and Ali, S.M. (2011) Effects of Different Fruit Juices Used as Carbon Source on Cucumber Seedling under in Vitro Cultures. African Journal biotechnology, 10, 7404-7408.

[30] Manawadu, I., Dahanayake, N., Senanayake, S.G.N. (2014) Effects of Different Natural Organic Additives on in Vitro Shoot Regeneration of Raphanus sativus L. var. Beeralu. Journal of Agricultural Science and Technology, A4, 219223.

[31] Rahman, A., Islam, M.O., Prodhan, A. and Ichihashi, S. (2004) Effects of Complex Organic Extracts on Plantlet Regeneration from PLBs and Plantlet Growth in the Doritaenopsis Orchid. Japan Agricultural Research Quarterly, 38, 55-59. http://dx.doi.org/10.6090/jarq.38.55 